\title{
Treatment of hemifacial spasm with botulinum toxin type a: effective, long lasting and well tolerated
}

\author{
Tratamento do espasmo hemi-facial com toxina botulínica tipo a foi efetivo, bem tolerado \\ e com efeito sustentado
}

Jean Pierre Mette Batisti', Alais Daiane Fadini Kleinfelder', Natália Bassalobre Galli1, Adriana Moro², Renato Puppi Munhoz ${ }^{3}$ Hélio Afonso Ghizoni Teive²

\begin{abstract}
Hemifacial spasm (HFS) is a common movement disorder characterized by involuntary tonic or clonic contractions of the muscles innervated by the facial nerve. Objective: To evaluate the long-term effect of botulinum toxin type A (BTX-A) in the treatment of HFS. Methods: A retrospective analysis of patients treated at the Movement Disorders Outpatient Clinic in the Neurology Service, Hospital de Clínicas, Federal University of Paraná, Curitiba, from 2009 to 2013 was carried out. A total of 550 BTX-A injections were administered to 100 HFS patients. Results: Mean duration of improvement following each injection session was 3.1 months, mean latency to detection of improvement was 7.1 days and mean success rate was $94.7 \%$. Patients were evaluated at an interval of 5.8 months after each application. Adverse effects, which were mostly minor, were observed in $37 \%$ of the patients at least once during follow-up. The most frequent was ptosis (35.1\%). Conclusion: Treatment of HFS with BTX-A was effective, sustainable and safe and had minimal, well-tolerated side effects.
\end{abstract}

Keywords: botulinum toxins; botulinum toxin type A; hemifacial spasm.

\section{RESUMO}

O espasmo hemifacial (EHF) é um distúrbio do movimento comum, caracterizado pela presença de contrações musculares tônicas ou clônicas dos músculos inervados pelo nervo facial. Objetivo: Avaliar o efeito em longo prazo do uso da toxina botulínica tipo A (TXB) no tratamento do espasmo hemifacial (EHF). Métodos: Foi realizada uma análise retrospectiva de pacientes do Ambulatório de Distúrbios do Movimento do departamento de Neurologia do Hospital das Clínicas da Universidade Federal do Paraná entre 2009 e 2013. Foram administradas 550 doses em 100 portadores de EHF. Resultados: A duração média de efeito foi de 3,14 meses, com latência de 7,10 dias e a taxa de sucesso foi de $94,73 \%$. Os pacientes foram reavaliados pelo médico em um intervalo de 5,76 meses após cada aplicação. Efeitos adversos transitórios, em sua maioria menores, foram observados em $37 \%$ dos pacientes ao menos uma vez durante o seguimento e o mais freqüente foi ptose palpebral (35,14\%). Conclusão: O tratamento do EHF com TXB-A mostrou-se eficaz, sustentado e seguro, com efeitos colaterais mínimos e bem tolerados.

Palavras-chave: toxinas botulínicas; toxina botulínica tipo A; espasmo hemifacial.

Hemifacial spasm (HFS) is a craniofacial movement disorder characterized by involuntary contractions of the muscles on one side of the face ${ }^{1}$. The most common site for the contractures is the orbicularis oculi muscle, but the corrugator supercilii, frontalis muscle, orbicularis oris, zygomaticus major and platysma can also be affected ${ }^{2}$. The condition is believed to be mainly due to a peripheral dysfunction of the facial nerve, occasionally associated with nerve compression by a blood vessel or tumor ${ }^{3,4}$. The pathophysiology, however, has yet to be fully elucidated as the condition can occur in the absence of structural alterations ${ }^{3}$. In a recent study, Wilkinson and Kaufmann ${ }^{5}$ showed that HFS may be associated with central nervous system changes. Accordingly, one previous study from our group found similar profiles of obsessive and psychiatric symptoms in cases of HFS and blepharospasm, which is recognized as a movement disorders of

'Universidade Federal do Paraná, Hospital de Clínicas, Curitiba PR, Brasil;

${ }^{2}$ Universidade Federal do Paraná, Hospital de Clínicas, Unidade de Distúrbios do Movimento,Departamento de Medicina Interna, Serviço de Neurologia, Curitiba PR, Brasil;

${ }^{3}$ University Health Network, Morton and Gloria Shulman Movement Disorders Centre and the Edmond J. Safra Program in Parkinson's Disease, Toronto Western Hospital, Toronto, Ontario, Canada.

Correspondence: Hélio A. G. Teive; Rua General Carneiro 1103/102; 80060-150 Curitiba PR, Brasil.E-mail: hagteive@mps.com.br

Conflict of interest: There is no conflict of interest to declare.

Received 12 March 2016; Received in final form 12 June 2016; Accepted 18 October 2016. 
pure central origin. ${ }^{6}$ The mean annual incidence is 0.81 per 100,000 women and 0.74 per 100,000 men. Because of this low incidence, there are few studies comparing the efficacy of different therapies ${ }^{7}$. Anticonvulsants such as carbamazepine and clonazepam should only be used for mild presentations, as results are typically unsatisfactory ${ }^{8}$. Microvascular surgery is another form of treatment and has a success rate ranging from $38.2 \%$ to $87 \%$ according to the literature. However, it is an invasive procedure that can lead to severe complications and is contraindicated for elderly individuals, patients with severe systemic diseases and patients whose symptoms are not caused by vascular compression. It is therefore not the therapy of first choice in most cases ${ }^{9}$. Botulinum toxin type A (BTX-A) has been used to treat HFS since the 1980s and provides symptom relief and improved quality of life in about $85 \%$ to $95 \%$ of cases $^{10}$. It is currently considered the gold standard for treatment of HFS as it can be administered in outpatient units, is less invasive than other therapies, and is well tolerated ${ }^{11}$. Botulinum toxin type $\mathrm{A}$ is an exotoxin that causes presynaptic blocking at the neuromuscular junction by inhibiting the release of acetylcholine ${ }^{12}$. As the effect of the toxin is reversible and, consequently temporary, patients must have regular injections to control the clinical manifestations of the disease ${ }^{13}$. It is therefore essential to investigate the efficacy and duration of the effect of BTX-A injections during treatment of HFS. However, few studies have analyzed the long-term efficacy of the toxin in the treatment of HFS in Brazil. In light of this, the present study sought to describe five years of experience with the use of BTX-A to treat HFS in a tertiary academic hospital.

\section{METHODS}

\section{Patients}

The study was carried out with patients seen in the Movement Disorders Outpatient Unit in the Neurology Service, Hospital de Clínicas, Federal University of Paraná (HC/UFPR), between January 2009 and December 2013. The inclusion criteria were as follows: 1 ) age 18 years or older; 2) clinically confirmed diagnosis of HFS; 3) regular follow up during the study period; and 4) signed voluntary consent to treatment with BTX-A. Exclusion criteria were: 1) incomplete medical records; 2) fewer than two BXT-A applications; and 3) an interval of more than one year between injection sessions. Using these criteria, of an initial sample of 136 patients treated with BTX-A in the period investigated, 100 were included in the study. The study was approved by the HC/UFPR Committee for Ethics in Human Research.

\section{Botulinum toxin A}

The study was retrospective, carried out with using demographic and clinical data from medical records of patients diagnosed with HFS. Ninety-five patients had primary FHS and five had postparalytic hemifacial spasm. All patients had neuroimaging tests (brain CT scan, complemented by brain MRI in 50 cases). Information about each injection session included date, dose, subjective latency to clinical improvement, duration of the beneficial effect of BTX-A, and efficacy using the Columbia University Rating Scale ${ }^{14}$. This scale is used in routine evaluation in the Botulinum Toxin Outpatient Clinic of HC-UFPR. Patients were assigned values to the results of the treatment between $0 \%$ and $100 \%$, where $0 \%$ corresponded to no improvement and $100 \%$ to complete improvement and a return to normal function.

Patients being followed during this period used onabotulinumtoxinA, Botox (Allergan Pharmaceuticals, CA, USA). The protocol used to administer BTX-A in our service is the protocol advocated by the Brazilian Ministry of Health $^{15}$. Botulinum toxin type A is diluted 2:1 with saline solution and injected in doses of 1 to 5 IU in the orbicularis oculi, procerus, corrugator supercilii, risorius, orbicularis oris, and platysma muscles. The dose administered varied during the treatment according to the response reported by each patient, the presence of side effects and clinical assessment, but in general, we used 5 units per injection around the eye, except, in the inferior muscle orbicularis oculi - 2 units, 2 units per injection around the mouth and chin, and, when necessary 5 units in the platysma muscle. The intervals between injection sessions varied according to the patient's response to the therapy.

\section{Statistical analysis}

The data collected were recorded on a Microsoft Excel ${ }^{\circ}$ spreadsheet and exported for analysis with the Statistica package from Statsoft ${ }^{\circ}$. The descriptive analysis of the efficacy and safety of BTX-A and the demographic variables included percentages and mean and standard deviation as appropriate.

\section{RESULTS}

Of the initial sample of 136 patients, six were excluded because they had had less than two BTX-A injection sessions during the study period and 30 because their medical records were incomplete. Hence, 100 patients were included in the statistical analysis. Mean patient age was 63.1 years, standard deviation (SD) of 12.4 years. Most patients were females $(72 \%)$, and the left hemiface was more frequently affected (61\% of cases).

Overall, 550 doses were administered to the 100 patients in the study period. Mean follow-up was 2.6 years (SD 1.4), and the mean number of injection sessions per patient was 5.5 (SD 2.3). Mean BTX-A dose was 28 IU (SD 8.6), and mean interval between injections was 5.8 months (SD 2.1). For $30 \%$ of the patients the final dose was higher than the initial, while for $35 \%$ it was lower due to the patient's response and occurrence of temporary side effects. Observed onset 
latency was around 7.1 days (SD 3.9), and mean effect duration 3.1 months (SD 1). On a subjective scale of $0 \%$ to $100 \%$ improvement, the effect of administration of BTX-A was $81 \%$ (SD 5.6\%).

Temporary side effects were observed following $6.7 \%$ of the injection sessions, and $37 \%$ of the patients presented with temporary adverse reactions at least once during follow-up (Figure). However, most of the side effects observed were minimal, the most common being eyelid ptosis, which was observed in $36.11 \%$ of the patients (Figure). There were no reports of any systemic or severe adverse effects. The overall success rate was $94.73 \%$ (of all the injection sessions). Twenty-one applications $(3.82 \%)$ resulted in a short-term effect of less than one month, seven $(1.27 \%)$ had no effect and one $(0.18 \%)$ had a slight effect.

Comparison of the main results with the findings of three clinical trials in the literature failed to reveal any significant differences (Table).

\section{DISCUSSION}

Our study demonstrated that mean improvement on a subjective functional improvement scale was $81 \%$, and mean effect duration was 12.56 weeks. These findings corroborate those published studies. ${ }^{16,17,18,19,20,21,22,23,24}$. The success rate in the present study was $94.73 \%$ when injections that did not produce any effect or produced a short-term or minor effect were excluded. This success rate is similar to that reported in two other studies $\left(90 \%{ }^{23}\right.$ and $\left.98 \%{ }^{24}\right)$. These data indicate that even in a teaching hospital, where there is a wide range of health professionals at different stages of their education and very often with little experience, the results are similar to those of other research centers that specialize in administration of the toxin. In this case series of HFS, the affected side of the face was the left side, predominantly in females patients. These data corroborate the findings of previously-published studies. ${ }^{16,17}$ The high incidence of left HFS could be explained by congenital malformations in the vascular system located primarily on the

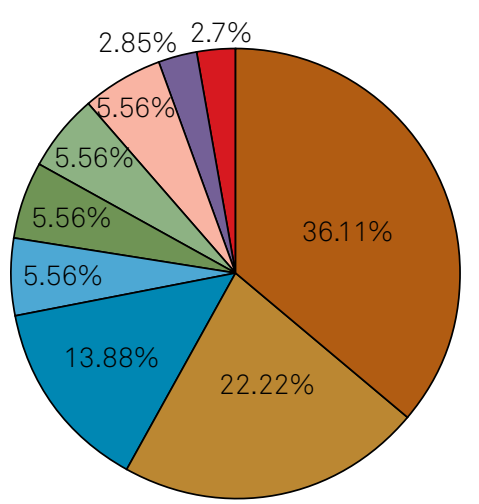

\begin{tabular}{|c|c|}
\hline Eyelid ptosis & $\begin{array}{l}\text { Orbicularis oris muscle } \\
\text { paralysis }\end{array}$ \\
\hline Lagophthalmos & $\begin{array}{l}\text { Peripheral facial nerve } \\
\text { paralysis }\end{array}$ \\
\hline Eye's irritation & Mild dysphagia \\
\hline Xerostomia & Pain \\
\hline
\end{tabular}

HFS: hemifacial spasm; BTS-a: botulinum toxin type A.

Figure. HFS treatment with BTX-A: transitory side effects.

Table. HFS -Treatment with BTX-A: Literature review.

\begin{tabular}{|c|c|c|c|c|}
\hline Characteristics & Batisti et al. & Barbosa et al. ${ }^{1} \square$ & Defazio et al.' ${ }^{\prime}$ & Thussu et al. ${ }^{1} \square$ \\
\hline Number of patients & 100 & 54 & 65 & 27 \\
\hline Mean age & 63.08 & 48.3 & 56 & 47.78 \\
\hline Gender (F\%) & 72 & 75.9 & 70 & 70.4 \\
\hline Side (L\%) & 61 & 61.1 & - & 51.85 \\
\hline Follow-up (years) & 2.64 & 5.88 & - & - \\
\hline Number of doses evaluated by study & 550 & 808 & 239 & 45 \\
\hline Average applications per patient & 5.48 & 14.96 & - & 1.67 \\
\hline Average dose per application & 27.98 & $\begin{array}{c}\text { Beginning } 34.47 \\
\text { End } 37.61\end{array}$ & $\begin{array}{l}\text { Beginning } 17.5 \\
\text { End } 15.9\end{array}$ & 74.37 \\
\hline Increase of dose (\%) & 30 & 11.1 & - & - \\
\hline Reduction of dose (\%) & 35 & 40.7 & - & - \\
\hline Latency (days) & 7.1 & - & - & 11.63 \\
\hline Average duration of effect (months) & 3.14 & $\begin{array}{c}\text { Beginning } 3.42 \\
\text { End } 3.22\end{array}$ & 3.5 & 4.46 \\
\hline Subjective evaluation (0-100\%) & 81 & $\begin{array}{l}\text { Beginning } 83.18 \\
\text { End } 78.53\end{array}$ & 96 & - \\
\hline Adverse effects on total applications (\%) & 6.73 & - & - & 4.37 \\
\hline Adverse effects of patients (\%) & 37 & 64.8 & 36.9 & - \\
\hline
\end{tabular}

The results were compared with three clinical trials. HFS: hemifacial spasm; BTX-A: botulinum toxin type A; (F\%): corresponds to female percentage of the subjects; Side (L) corresponds to left side affected subjects. In two studies, the average dose application was evaluated on the first and last reported dose. The increase or reduction of dose refers to a difference between the administration of the first and last dose of the Botulinum Toxin Type A. 
left-hand side ${ }^{25}$; however, to the authors' knowledge, there are no studies with statistically significant results that support this hypothesis.

Mean patient age was similar to that in a study carried out in southeast Brazil' ${ }^{26}$. According to Thussu et al. ${ }^{18}$, the response to therapy is not influenced by variables such as age group, gender, side of the face affected, age of onset and duration of symptoms prior to treatment with BTX-A. Mean latency (7.1, SD 3.94) was very similar to that observed by Kollewe et al. ${ }^{27}$ and Lin et al. ${ }^{28}$, who reported figures of 7.1 days (SD 2.3) and 5.0 days (SD 4.7), respectively. However, in another study, symptoms in HFS patients were reported to disappear between seven and 30 days after injection of BTX-A, with a mean of 11.63 days (SD 7.07) ${ }^{18}$. This difference may be a result of the difference in sample size and the variability in patient response.

The mean time between patient visits was 23.04 weeks. Patients therefore remained without the benefit of BTX-A injections for approximately 10 weeks. This discrepancy between effect duration and the interval between injections in our service is a result of administrative and financial problems, as the number of physicians is not proportional to the number of patients seen, resulting in longer waiting times. However, if the mean effect duration of BTX-A injections is known, a return visit can be scheduled based on this and the interval can be increased or decreased according to the observed response of each patient to the therapy. To improve the quality of life of HFS patients and the service they receive, return visits should be scheduled for three months after injection of the toxin.

Although no systemic or severe side effects were observed in our study, at least one adverse effect was reported by $37 \%$ of the patients followed up. The most common complaint was ptosis, reflecting the findings of Rieder et $\mathrm{al}^{20}$. According to the literature, the frequency of adverse events varies from $20 \%^{29}$ to $64.8 \%{ }^{17,30}$. This variation is probably a result of the fact that some studies are based on patient-reported data and others on a physician's clinical diagnosis. In various studies, ptosis was the most common adverse effect and no systemic or major adverse events were reported ${ }^{17,29,30}$. The total incidence of adverse effects in the present study was probably lower because of information bias, as the incidence of side effects was determined based on information supplied by patients during their return visits. Another important point is that all patients with HFS were injected by fellows of the movement disorders unit or neurology residents from our institution.

Injection of BTX-A proved unsuccessful in $1.27 \%$ of cases. Nevertheless, a recent study by Czyz et al. ${ }^{29}$ showed that even with long-term follow-up there were no reports of resistance to BTX-A. This difference may be because ours is a tertiary center, where cases of HFS tend to be more severe and complex. Nevertheless, as there are few cases of resistance to BTX-A described in the literature, the pathophysiology of this resistance has yet to be clarified. A study carried out at Ohio State University College of Medicine showed that there was no statistically significant difference in the correlation between the incidence of side effects, dose and effect duration between the first and last injection $^{29}$. We could not make this comparison in our study because of confounding factors and selection bias, as not all of the patients were followed up from the beginning of the BTX-A therapy.

Although various studies have shown that BTX-A is the gold standard for treatment of HFS, few have investigated resistance to BTX-A or whether the dose needs to be increased in the long term. New long-term, prospective clinical trials should therefore be carried out to assess the efficacy of the toxin in this regard. This study is in accordance with several studies published previously, however, it is necessary to emphasize that the botulinum toxin application was by neurology medical residents and fellows of the movement disorders unit.

In conclusion, the findings of the present study show that treatment of HFS with BTX-A was effective, long-lasting and well-tolerated by patients. Furthermore, there were no reports of severe or permanent adverse effects that would prevent the treatment being continued.

\section{References}

1. Abbruzzese G, Berardelli A, Defazio G. Hemifacial spasm. Handb Clin Neurol. 2011;100:675-80. http://doi.org/10.1016/B978-0-444-52014-2.00048-3

2. Sorgun MH, Yilmaz R, Akin YA, Mercan FN, Akbostanci MC Botulinum toxin injections for the treatment of hemifacial spasm over 16 years. J Clin Neurosci. 2015;22(8):1319-25. http://doi.org/10.1016/j.jocn.2015.02.032.

3. Yaltho TC, Jankovic J. The many faces of hemifacial spasm: differential diagnosis of unilateral facial spasms. Mov Disord. 2011;26(9):1582-92. http://doi.org/10.1002/mds.23692

4. Norton J. Is hemifacial spasm of peripheral or central origin? Can J Neurol Sci. 2014;41(2):142. http://doi.org/10.1017/S0317167100016498
5. Wilkinson MF, Kaufmann AM. Facial motor neuron excitability in hemifacial spasm: a facial MEP study. Can J Neurol Sci. 2014;41(2):239-45. http://doi.org/10.1017/S0317167100016644

6. Munhoz RP, Teive HA, Della Coletta MV, Germiniani FM, Iwamoto FM, Camargo $\mathrm{CH}$ et al. Frequency of obsessive and compulsive symptoms in patients with blepharospasm and hemifacial spasm. Arq Neuropsiquiatr. 2005;63(2A):213-6. http://doi.org/10.1590/S0004-282X2005000200004

7. Rosenstengel C, Matthes M, Baldauf J, Fleck S, Schroeder H. Hemifacial spasm: conservative and surgical treatment options. Dtsch Arztebl Int.. 2012;109(41):667-73. http://doi.org/10.3238/arztebl.2012.0667 
8. Wang A, Jankovic J. Hemifacial spasm: clinical findings and treatment. Muscle Nerve. 1998;21(12):740-7. http://doi.org/10.1002/ (SICI)1097-4598(199812)21:12<1740::AID-MUS17>3.0.CO;2-V

9. Park HL, Lim SM, Kim TH, Kang KH, Kang H, Jung YH et al. Intractable hemifacial spasm treated by pulsed radiofrequency treatment. Korean J Pain. 2013;26(1):62-4. http://doi.org/10.3344/kjp.2013.26.1.62

10. Singh S. Botulinum toxin in hemifacial spasm: revisited. Indian J Plast Surg. 2013;46(1):159-60. http://doi.org/10.4103/0970-0358.113746

11. Mezaki T. [Clinical application of botulinum toxin]. Brain Nerve. 2011;63(7):785-94. Japanese.

12. Hallett M, Albanese A, Dressler D, Segal KR, Simpson DM, Truong D et al. Evidence-based review and assessment of botulinum neurotoxin for the treatment of movement disorders. Toxicon. 2013;67:94-114. http://doi.org/10.1016/j.toxicon.2012.12.004

13. Xu YP, Shen J, Zhu QB, Gu J, Lin SZ, Fan JP. Efficacy of botulinum toxin A for treatment of unilateral spasms of the eyelid and its prognosis. Eur Rev Med Pharmacol Sci. 2013;17(21):2974-9.

14. Brin MF. Botulinum toxin: chemistry, pharmacology, toxicity and immunology. Muscle Nerve Suppl. 1997;6:S146-68.

15. Ministério da Saúde (BR). Portaria № 376, de 13 de abril de 2016. Habilita o Hospital da Mulher como unidade de assistência de alta complexidade em neurocirurgia. Diário Oficial União. 15 abr 2016;seção 1:39.

16. Felicio AC, Godeiro Junior CO, Borges V, Silva S, Ferraz HB. Clinical assessment of patients with primary and postparalytic hemifacia spasm: a retrospective study. Arq Neuropsiquiatr. 2007;65(3B):783-6. http://doi.org/10.1590/S0004-282X2007000500009

17. Barbosa ER, Takada LT, Gonçalves LR, Costa RM, Silveira-Moriyama L, Chien HF. Botulinum toxin type A in the treatment of hemifacial spasm: an 11-year experience. Arq Neuropsiquiatr. 2010;68(4):502-5. http://doi.org/10.1590/S0004-282X2010000400006

18. Thussu A, Barman C, Prabhakar S. Botulinum toxin treatment of hemifacial spasm and blepharospasm : objective response evaluation. Neurol India. 1999;47(3):206-9.

19. Bares M, Streitova H. Long-term therapy of benign essential blepharospasm and facial hemispasm with botulinum toxin A : retrospective assessment of the clinical and quality of life impact in patients treated for more than 15 years. Acta Neurol Belg. 2014:45:1-7. http://doi.org/10.1007/s13760-014-0285-z

20. Wu CJ, Shen JH, Chen Y, Lian YJ. Comparison of two different formulations of botulinum toxin a for the treatment of blepharospasm and hemifacial spasm. Turkish Neurosurg. 2011;21(4):625-9.
21. Rieder CRM, Schestatsky P, Socal, MP, Monte TL, Fricke D, Costa J. A double-blind, randomized, crossover study of prosigne versus botox in patientswithblepharospasmandhemifacialspasm.ClinNeuropharmacol. 2007;30(1) 39-42. http://doi.org/10.1097/01.WNF.0000236771.77021.3C

22. Quagliato EM, Carelli EF, Viana MA. Prospective, randomized, double-blind study, comparing botulinum toxins type a botox and prosigne for blepharospasm and hemifacial spasm treatment. Clin Neuropharmacol .2010;33(1):27-31. http://doi.org/10.1097/WNF.0b013e3181c46f61

23. Cannon PS, MacKenzie KR, Cook AE, Leatherbarrow B. Difference in response to botulinum toxin type A treatment between patients with benign essential blepharospasm and hemifacial spasm. Clin Experiment Ophthalmol. 2010;38(7):688-91. http://doi.org/10.1111/j.1442-9071.2010.02303.x

24. Cillino S, Raimondi G, Guépratte N, Damiani S, Cillino M, Di Pace F, Casuccio A. Long-term efficacy of botulinum toxin A for treatment of blepharospasm, hemifacial spasm, and spastic entropion: a multicentre study using two drug-dose escalation indexes. Eye (Lond). 2010;24(4):600-7. http://doi.org/10.1038/eye.2009.192

25. Defazio G, Berardelli A, Abbruzzese G, Coviello V, De Salvia R, Federico F et al. Primary hemifacial spasm and arterial hypertension: a multicenter case-control study. Neurology. 2000;54(5):1198-200. http://doi.org/10.1212/WNL.54.5.1198

26. Schellini SA, Matai O, Igami TZ, Padovani CR, Padovani CP. [Essential blepharospasm and hemifacial spasm: characteristic of the patient, botulinum toxin a treatment and literature review]. Arq Bras Oftalmol. 2006;69(1):23-6. Portuguese. http://doi.org/10.1590/S0004-27492006000100005

27. Kollewe K, Mohammadi B, Dengler R, Dressler D. Hemifacial spasm and reinnervation synkinesias: long-term treatment with either Botox or Dysport. J Neural Transm (Vienna). 2010;117(6):795-63. http://doi.org/10.1007/s00702-010-0409-4

28. Wang L, Hu X, Dong H, Wang W, Huang Y, Jin L et al. Clinical features and treatment status of hemifacial spasm in China. Chin Med $J$ (Engl). 2014;127(5):845-9.

29. Czyz CN, Burns JA, Petrie TP, Watkins JR, Cahill KV, Foster JA. Long-term botulinum toxin treatment of benign essential blepharospasm, hemifacial spasm, and Meige syndrome. Am J Ophthalmol. 2013;156(1):173-7.e2. http://doi.org/10.1016/j.ajo.2013.02.001

30. Mejia NI, Vuong KD, Jankovic J. Long-term botulinum toxin efficacy, safety, and immunogenicity. Mov Disord. 2005;20(5):592-7. http://doi.org/10.1002/mds.20376 